Eos, Vol. 90, No. 14, 7 April 2009

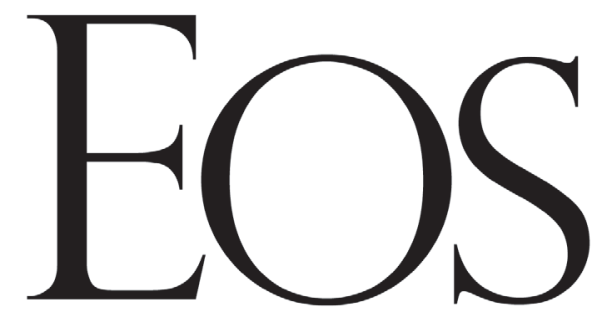

VOLUME 90 NUMBER 14

7 APRIL 2009

PAGES 117-128

\section{Nutrient Enrichment Drives Gulf of Mexico Hypoxia}

\section{PAGES 117-118}

During most summers over the past 30 years, bottom dissolved oxygen across a large area of the Louisiana and upper Texas continental shelf declined to concentrations too low (hypoxia) for most fish and large invertebrate animals to survive. This area is one of the best known "dead zones" proliferating around the world [Diaz and Rosenberg, 2008]. During July 2008, hypoxic bottom waters extended across 20,720 square kilometers (Figure 1), but they were probably even more extensive because winds from Hurricane Dolly mixed the waters off Texas before the survey could be completed.

Increased inputs of nutrients (principally nitrogen and phosphorus) from the U.S. agricultural heartland within the Mississippi-Atchafalaya River Basin (MARB) are implicated in the development and spread of hypoxia in the Gulf of Mexico. Consequently, the causes of, and solutions for, hypoxia have been subjects of extensive debate and analysis. An integrated scientific assessment led to a 2001 Action Plan [Mississippi River/Gulf of Mexico Watershed Nutrient Task Force, 2001] with a goal of reducing the area of the hypoxic zone to less than 5000 square kilometers by reducing nitrogen loading [Rabalais et al., 2007].

\section{Consensus and Skepticism}

As part of a reassessment of the Action Plan completed in 2008, the U.S. Environmental Protection Agency's Science Advisory Board (SAB) conducted another evaluation of the state of the science regarding hypoxia. An SAB panel (including three article coauthors, Walter R. Boynton, Robert W. Howarth, and James G. Sanders) concluded, "Recent science has affirmed the basic conclusion that contemporary changes in the hypoxic area in the northern Gulf of Mexico

By D. F. Boesch, W. R. Boynton, L. B. Crowder, R. J. Diaz, R. W. Howarth, L. D. MeE, S. W. NixON, N. N. Rabalais, R. RosenberG, J. G. SANDERS, D. SCAVIA, AND R. E. TURNER are primarily related to nutrient fluxes from the MARB" [SAB, 2008, p. 2]. The reconents stimulate the production of planktonic organic matter, the decomposition of which depletes dissolved oxygen in bottom waters on the seasonally stratified inner shelf.

Despite these two major scientific assessments supporting this consensus, skeptics [Dagg et al., 2007; Bianchi et al., 2008] have suggested alternative causes of hypoxia, including (1) oxidation of organic matter not derived from phytoplankton production, (2) physical processes affecting water column stability, and (3) coastal wetland loss and river controls. This article addresses these criticisms and demonstrates why they do not challenge the consensus on nutrient enrichment.

\section{Organic Matter Sources}

Seasonally recurring hypoxia developed on the shelf from the 1970s through the 1990s, coinciding with a tripling of nitrate firmed consensus is that anthropogenic nutri- loading from the MARB between the 1950s and 1990, but not with changes in stratification or external sources of organic matter $[S A B, 2008]$. While there has been a massive loss of coastal wetlands since the 1930s, the loss rate peaked in the 1960s and has since declined [Barras et al., 2008]. Furthermore, there is no corroborating spatiotemporal, biochemical, or isotopic evidence suggesting that a significant amount of this marsh-derived organic matter enters the bottom waters of the hypoxic zone [Turner et al., 2007]. Most of the organic matter is likely redeposited or metabolized within the estuarine-wetland complex or is transported offshore in surface waters in dissolved form [SAB, 2008]. Little wetland-derived organic carbon is found in sediments beyond the coastal bays [Gordon and Goñi, 2003]. The nonmarine organic matter in shelf sediments is highly refractory and resistant to further decomposition. The average age of this terrestrial organic matter is 2400 years, and it is mainly derived from degraded plant material in midwestern soils.

Except where light penetration allows benthic photosynthesis, bottom sediments are reservoirs, not sources, of organic matter. Benthic respiration is the predominant cause of oxygen depletion during summer [Quiñones-Rivera et al., 2007] and is ultimately dependent on utilizable organic

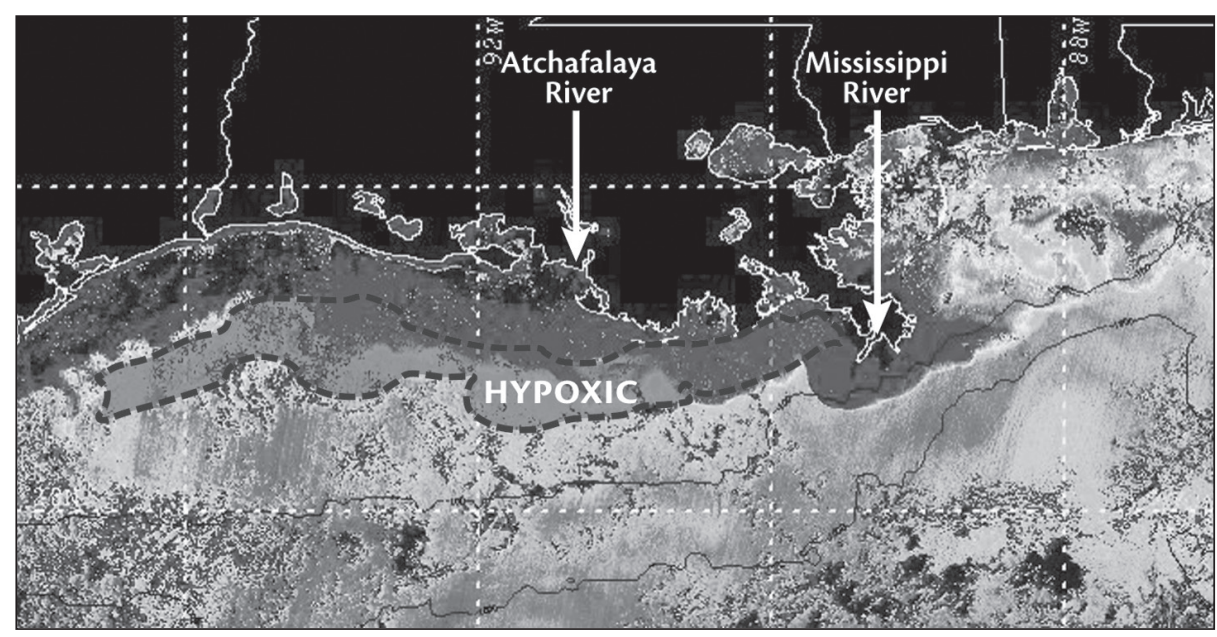

Fig. 1. High chlorophyll a concentrations along the inner shelf off Louisiana and Texas (orange and red) on 11 June 2008 (Indian Space Research Organization Oceansat 1 Ocean Color Monitor image provided by the Louisiana State University (LSU) Earth Scan Laboratory; http://www .esl.lsu.edu/imagery/ocm/) in relation to an overlay of the bottom hypoxia (<2 milligrams per liter, gray area outlined by dashes) during 21-27 July 2008. In June, chlorophyll a concentrations ranged from 22 micrograms per liter (inshore) to 7 micrograms per liter (offshore) (N. N. Rabalais, unpublished data, 2008). Original color image appears at the back of this volume. 
matter delivered to the seabed. Although some of this labile carbon comes from terrestrial and estuarine sources, evidence suggests that it originates predominantly from nutrient-enhanced shelf production.

There is overwhelming evidence that riverine nutrients drive both the production of phytoplankton and the size of the hypoxic zone on the inner shelf. The seasonal flux of nitrate is the strongest statistical determinant of phytoplankton biomass and production [Turner et al., 2007; Green and Gould, 2008; Lohrenz et al., 2008]. Changes in phosphorus (P) flux as hypoxia developed in the Gulf of Mexico remain unknown, because regular measurements of P began only in 1974 . However, reconstructed loads and model hindcasts suggest that increased loads of nitrogen $(\mathrm{N})$, not $\mathrm{P}$, were the principal drivers of increased hypoxia since the mid-1970s [Scavia and Donnelly, 2007]. P may limit spring phytoplankton production [Dagg et al., 2007], particularly near the Mississippi River discharge, where there is a surplus of $\mathrm{N}$ with respect to $\mathrm{P}$ needed to meet phytoplankton nutritional requirements. However, organic matter produced in the immediate surface discharge plume (within 100 kilometers of the main river mouth) contributes little of the organic matter causing hypoxia because the plume lies mostly in water deeper than the 10- to 30-meter depths where hypoxia regularly forms.

The highly productive inner shelf along the entire Louisiana coast, apparent in satellite-derived distributions of surface chlorophyll concentrations [Walker and Rabalais, 2006; Green and Gould, 2008], is very likely the primary source of the organic matter causing oxygen depletion. This band of surface water extends 400 kilometers or more along the coast and is fed directly by the Atchafalaya River discharge, as well as by that part of the Mississippi River discharge entrained in the Louisiana Coastal Current. The surface water overlies the majority of area covered by hypoxic bottom water, into which it can directly supply labile organic matter. The high primary production in this coastal boundary layer is almost certainly sustained by nutrient recycling through processes meriting future research [SAB, 2008].

\section{Stratification and Physical Dynamics}

From the earliest papers on Gulf hypoxia, density stratification has consistently been considered a requirement for development of hypoxia. Strong stratification develops because freshwater discharges decrease the density of surface waters, although temperature is also an important contributor to these density differences. Energetic winds can break down stratification and reoxygenate bottom waters, but hypoxia can quickly return once stratification is reestablished [Rabalais et al., 2007]. Stratification alone is insufficient to deplete the oxygen inventories of waters beneath the density discontinuity; the consumption of oxygen faster than its resupply is also required [Hetland and DiMarco, 2007].

Bianchi et al. [2008] suggest that shelf hypoxia west of the Atchafalaya River is controlled primarily by density stratification and benthic respiration and therefore will not respond to reductions in riverine nutrient loading. However, the labile organic matter supporting benthic respiration must be derived predominantly from planktonic production either from the overlying surface water or, through advection, from highly productive waters just inshore. During spring, the westward flowing coastal current causes downwelling [Wiseman et al., 2004] that can translocate settling and resuspended organic matter as well as low-oxygen bottom water offshore in subsurface layers.

After the clearing of logjams around 1840, the Atchafalaya River began to capture an increasing portion of flow from the MARB, reaching $10 \%$ by $1890,30 \%$ by 1950 , and $35 \%$ by 1973. The Old River Control Structure was built to constrain, not to divert, flow to an average of $30 \%$ of the total MARB flow. The greater flow down the Atchafalaya certainly increased both stratification and river-enriched production on the western Louisiana shelf, thereby making this area more susceptible to hypoxia. However, the currently prevailing flows preceded by 20 or more years the development of recurrent hypoxia.

\section{Modeling Responses to Nutrient Inputs}

Understanding and forecasting Gulf hypoxia require a range of modeling approaches [SAB, 2008]. In lieu of a highly detailed understanding of the biophysical dynamics of the shelf ecosystem, several empirical or statistical models have been developed that have reasonable skill in hindcasting and forecasting the severity and extent of hypoxia based on river discharge and nitrate flux [Justić et al., 2007]. While physical modelers have criticized these models as overly simple [Hetland and DiMarco, 2007], some of the models incorporate calibrations representing the important processes of differential advection of surface and bottom water and the settling of continuously produced organic matter [Scavia and Donnelly, 2007].

Detailed physical and biological models can provide information on processes controlling the seasonal formation and dissipation of hypoxia, but such models are also based on numerous limiting assumptions. For example, Hetland and DiMarco's [2007] application of a physically complex model did not vary respiration as a function of organic matter supply but instead selected respiration rates required to constrain hypoxia to the regions in which it is observed. While more detailed and realistic models should be pursued, simpler models have an advantage for policy analysis because they have been tested against policy-relevant observations (e.g., hypoxic area) and process rates (e.g., summer average respiration rates).

\section{Moving Forward}

The compelling evidence that Gulf hypoxia is driven by anthropogenic nutrient enrichment in the MARB forms the basis for the recent recommitment by the federal-state interagency task force to the 2001 Action Plan, with its continued emphasis on nitrogen load reductions and the explicit addition of phosphorus reductions. Hypoxia has developed or expanded as a result of increased nutrient loading in a wide range of coastal systems, including other open continental shelves influenced by large river discharges (e.g., the eastern North Sea, northwestern Black Sea, and East China Sea). Nutrient load reduction goals have been set for many of these coastal systems, and mitigation strategies are being actively pursued. Although the northern Gulf of Mexico has its unique characteristics, it would be quite surprising-from this global perspective-if recurrent hypoxia had not also developed on this physically stratified, microtidal shelf with its large agricultural drainage basin.

Expanding dead zones are exacting increasing losses of fisheries production and the services provided by coastal marine ecosystems [Diaz and Rosenberg, 2008]. Skepticism about the consequences of Gulf hypoxia [Bianchi et al., 2008] ignores a growing literature documenting effects on the ecosystem (e.g., benthic biodiversity and food chain dynamics) and on valued resource species, such as bottom fish and shrimp. While remaining scientific questions merit continued research [SAB, 2008], evidence clearly supports the implementation of the nutrient load reductions specified by the updated Action Plan, in coordination with the restoration of Louisiana's coastal wetlands, in order to recover and sustain the resources and services provided by this important ecosystem.

Additional information and references can be found in the electronic supplement to this Eos issue (http://www.agu.org/eos _elec/).

\section{References}

Barras, J. A., J. C. Bernier, and R. A. Morton (2008), Land area change in coastal Louisiana-A multidecadal perspective (from 1956 to 2006), U.S. Geol. Surv. Sci. Invest. Map, 3019, 14 pp.

Bianchi, T. S., S. F. DiMarco, M. A. Allison, P. Chapman, J. H. Cowan Jr., R. D. Hetland, J. W. Morse, and $\mathrm{G}$. Rowe (2008), Controlling hypoxia on the U.S. Louisiana shelf: Beyond the nutrient centric view, Eos Trans. AGU, 89(26), 236-237.

Dagg, M. J., J. W. Ammerman, R. M. W. Amon, W. S. Gardner, R. E. Green, and S. E. Lohrenz (2007), A review of water column processes influencing hypoxia in the northern Gulf of Mexico, Estuaries Coasts, 30, 735-752.

Diaz, R. J., and R. Rosenberg (2008), Spreading dead zones and consequences for marine ecosystems, Science, 321, 926-929.

Gordon, E. S., and M. A. Goñi (2003), Sources and distribution of terrigenous organic matter delivered by the Atchafalaya River to sediments in the 
northern Gulf of Mexico, Geochim. Cosmochim. Acta, 67, 2359-2375.

Green, R. E., and R. W. Gould Jr. (2008), A predictive model for satellite-derived phytoplankton absorption over the Louisiana shelf hypoxic zone: Effects of nutrients and physical forcing, J. Geophys. Res., 113, C06005, doi:10.1029/ 2007JC004594.

Hetland, R. D., and S. F. DiMarco (2007), How does the character of oxygen demand control the structure of hypoxia on the Texas-Louisiana continental shelf?, J. Mar. Syst., 70, 49-62.

Justić, D., V. J. Bierman Jr., D. Scavia, and R. Hetland (2007), Forecasting Gulf's hypoxia: The next 50 years?, Estuaries Coasts, 30, 791-801.

Lohrenz, S. E., D. G. Redalje, W. J. Cai, J. Acker, and M. Dagg (2008), A retrospective analysis of nutrients and phytoplankton productivity in the Mississippi River plume, Cont. Shelf Res., 28, 1455-1475.

Mississippi River/Gulf of Mexico Watershed Nutrient Task Force (2001), Action plan for reducing, mitigating, and controlling hypoxia in the northern Gulf of Mexico, 36 pp., Environ. Prot. Agency, Washington, D. C. (Available at http://www.epa .gov/msbasin/pdf/actionplan2001.pdf)
Quiñones-Rivera, Z. J., B. Wissell, D. Justic, and B. Fry (2007), Partitioning oxygen source and sinks in a stratified coastal ecosystem using stable oxygen isotopes, Mar. Ecol. Prog. Ser., 342, 69-83.

Rabalais, N. N., R. E. Turner, B. K. Sen Gupta, D. F. Boesch, P. Chapman, and M. C. Murrell (2007),

Hypoxia in the northern Gulf of Mexico: Does the science support the plan to reduce, mitigate and control hypoxia?, Estuaries Coasts, 30, 753-772.

Scavia, D., and K. A. Donnelly (2007), Reassessing hypoxia forecasts for the Gulf of Mexico, Environ Sci. Technol., 41, 8111-8117.

Science Advisory Board (2008), Hypoxia in the northern Gulf of Mexico: An update by the EPA Science Advisory Board, EPA-SAB-08-003, Environ. Prot. Agency, Washington, D. C.

Turner, R. E., N. N. Rabalais, R. B. Alexander, G. McIsaac, and R. W. Howarth (2007), Characterization of nutrient and organic carbon and sediment loads and concentrations from the Mississippi River into the northern Gulf of Mexico, Estuaries Coasts, 30, 773-790.

Walker, N. D., and N. N. Rabalais (2006), Relationships among satellite chlorophyll $a$, river inputs, and hypoxia on the Louisiana continental shelf, Gulf of Mexico, Estuaries Coasts, 29, 1081-1093.
Wiseman, W. J., Jr., N. N. Rabalais, R. E. Turner, and D. Justić (2004), Hypoxia and the physics of the Louisiana Coastal Current, in Dying and Dead Seas: Climatic Versus Anthropic Causes, edited by J. C. L. Nihoul et al., pp. 359-372, Springer, New York.

\section{Author Information}

Donald F. Boesch and Walter R. Boynton, University of Maryland Center for Environmental Science, Cambridge; E-mail: boesch@umces.edu; Larry B. Crowder, Duke University, Beaufort, N. C.; Robert J. Diaz, Virginia Institute of Marine Science, Gloucester Point; Robert W. Howarth, Cornell University, Ithaca, N. Y.; Laurence D. Mee, Scottish Association of Marine Science, Oban, UK; Scott W. Nixon, University of Rhode Island, Narragansett; Nancy N. Rabalais, Louisiana Universities Marine Consortium, Chauvin; Rutger Rosenberg, Gothenberg University, Fiskebäckskil, Sweden; James G. Sanders, Skidaway Institute of Oceanography, Savannah, Ga.; Donald Scavia, University of Michigan, Ann Arbor; and R. Eugene Turner, Louisiana State University, Baton Rouge

\section{Grid Computing for Earth Science}

\section{PAGES 117, 119}

The fundamental challenges facing humankind at the beginning of the 21st century require an effective response to the massive changes that are putting increasing pressure on the environment and society. The worldwide Earth science community, with its mosaic of disciplines and players (academia, industry, national surveys, international organizations, and so forth), provides a scientific basis for addressing issues such as the development of new energy resources; a secure water supply; safe storage of nuclear waste; the analysis, modeling, and mitigation of climate changes; and the assessment of natural and industrial risks. In addition, the Earth science community provides short- and medium-term prediction of weather and natural hazards in real time, and model simulations of a host of phenomena relating to the Earth and its space environment. These capabilities require that the Earth science community utilize, both in real and remote time, massive amounts of data, which are usually distributed among many different organizations and data centers.

The Earth science community can benefit greatly from technology that can provide ready access to computing resources and services, easily managed data and metadata storage in distributed systems or in data centers, clearly defined data policy, authentication, confidentiality, and electronic collaboration. Grid infrastructure and systems meet these requirements as a distributed resource system. Grid computing permits the sharing of resources between institutions and allows

By P. Renard, V. Badoux, M. Petitdidier, AND R. COSSU for scaling up computing power and storage capacity in a way that is impossible for a single institution to do. Also, grid computing offers a transparent collaborative platform for users, allowing them to have access to more resources at a given time. This access is especially important for exploiting large data sets scattered in several locations, for running large statistical jobs, and for sharing data and algorithms among many partners without the need for conversions.

Earth science computing and data management needs traditionally have been provided for by local and national institutions. The limitations of cost and the number of computer central processing units (CPUs) available at any one site can be overcome by geographically distributed systems for accessing data, computing resources, and Web services. Geographically distributed computing began by catering to specialized purposes or particular user groups (e.g., the Distributed European Infrastructure for Supercomputing Applications). The Berkeley Open Infrastructure for Network Computing (BOINC), introduced in 1999, pioneered the use, on a volunteer basis, of the enormous processing power of personal computers (PCs) around the world. Earth scientists adopted BOINC only for specific climate and hydrology applications because it is not general enough and does not handle the problems of PC heterogeneity and confidentiality requirements.

\section{Grid Computing}

Grid computing emerged more than 10 years ago [Foster and Kesselman, 1998] as one type of distributed resource system. Grid computing consists of a network infrastructure comprising loosely coupled heterogeneous data storage and computing resources connected via the Internet and controlled for management and access by software (middleware) such as gLite, UNICORE, Globus Toolkit, and GRIA. A grid system is based on long-term and dynamic collaboration among grid partners (resource providers and user communities) with a trust agreement to guarantee security and confidentiality. A user must be authorized by a certification authority and must belong to a recognized virtual organization: a user community providing the rights to access to grid resources (computing, storage, data, software, services). The user can then execute simple tasks (jobs) or complex computation workflow operations by specifying only the characteristics of the computing resources needed and a logical name for data to be accessed via the grid storage.

Because of its architecture, a grid can efficiently tackle a large ensemble of computations running independently. A grid is also ideally suited for analyzing and producing large data sets and for sharing data within large teams. Several grid infrastructures have already been deployed around the world, for example, in North and South America, Asia, Australia, North Africa, and in 2008 in Senegal.

The largest grid deployment to date, Enabling Grids for E-Science (EGEE; http:// www.eu-egee.org/), is designed for analyzing petabytes of data that will be produced by the European Organization for Nuclear Research's (CERN) Large Hadron Collider experiment in Geneva, Switzerland. Access to EGEE is not restricted to high-energy physics and is currently used by other scientific communities including bioinformatics, Earth sciences, and astronomy. As of March 2009, 
Eos, Vol. 90, No. 14, 7 April 2009

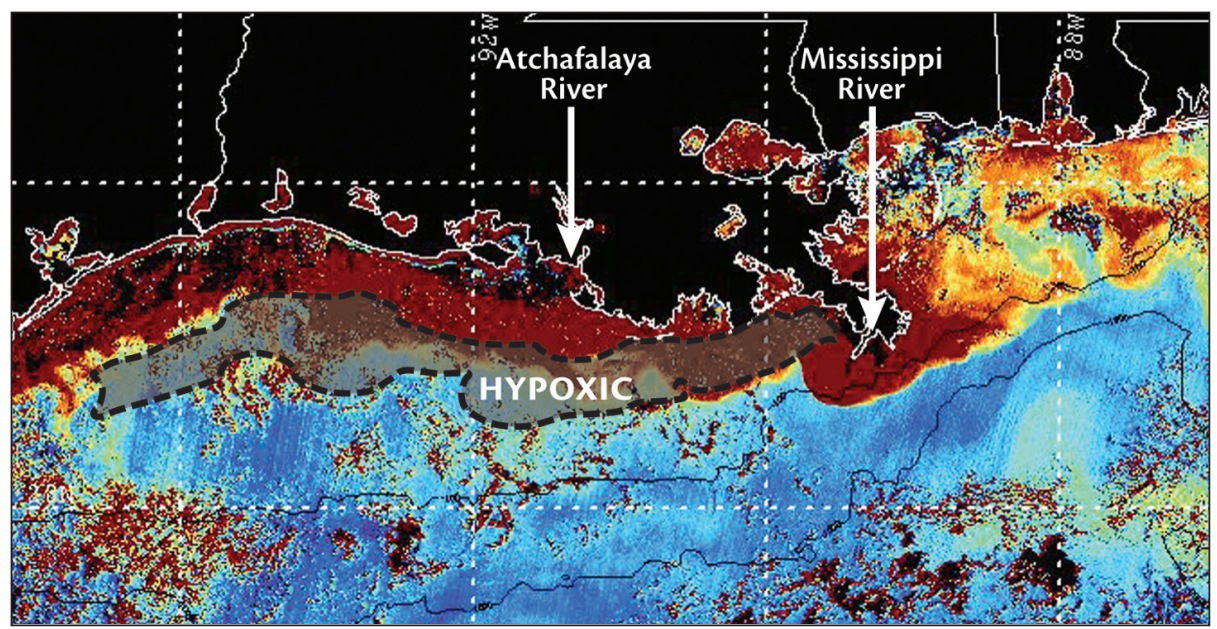

Page 117

Fig. 1. High chlorophyll a concentrations along the inner shelf off Louisiana and Texas (orange and red) on 11 June 2008 (Indian Space Research Organization Oceansat 1 Ocean Color Monitor image provided by the Louisiana State University (LSU) Earth Scan Laboratory; http://www .esl.lsu.edu/imagery/ocm/) in relation to an overlay of the bottom hypoxia $(<2$ milligrams per liter, gray area outlined by dashes) during 21-27 July 2008. In June, chlorophyll a concentrations ranged from 22 micrograms per liter (inshore) to 7 micrograms per liter (offshore) (N. N. Rabalais, unpublished data, 2008). 